\title{
Effect of photoinitiator concentration on marginal and internal adaptation of experimental composite blends photocured by modulated methods
}

\author{
Roberta Caroline Bruschi Alonsoํㅜ, Eduardo José Carvalho de Souza-Júnior², \\ Diogo Dressano², Giovana Albamonte Spagnolo de Araújo², José Manuel Ces \\ Rodriguez $^{1}$, Vinícius Di Hipólito ${ }^{1}$, Camillo Anauate-Netto ${ }^{1}$, Regina Maria Puppin-Rontani ${ }^{3}$, \\ Mario Alexandre Coelho Sinhoreti ${ }^{2}$
}

Correspondence: Dr. Roberta Caroline Bruschi Alonso Email: robalonso@yahoo.com

\begin{abstract}
'Biomaterials, Bandeirante Anhanguera University (UNIBAN), Rua, Maria Candida, 1813 - Bloco G - $6^{\circ}$ Andar, São Paulo, SP, Brazil, 2Department of Restorative Dentistry, Dental Materials, Piracicaba Dental School (Fop-Unicamp), Avenida Limeira, 901 Piracicaba, SP, Brazil, ${ }^{3}$ Department of Pediatric Dentistry, Piracicaba Dental School (Fop-Unicamp), Avenida Limeira, 901 Piracicaba, SP, Brazil
\end{abstract}

\section{ABSTRACT}

Objective: The aim of this study was to evaluate the influence of photoinitiator concentration on marginal and internal adaptation of composites photocured by modulated methods. Materials and Methods: Composites based on BisGMA/triethylene glycol dimethacrylate and $65 \mathrm{wt} \%$ of filler were prepared with different concentrations of camphorquinone/amine (C1- $0.5 \%, \mathrm{C} 2-1 \%$, C3-1.5\%). Cavities were prepared ( $3 \mathrm{~mm} \times 3 \mathrm{~mm} \times 2 \mathrm{~mm}$ ) on the buccal surface of 120 bovine incisors and the adhesive system Adper Single Bond 2 was applied following manufactures instruction. Specimens were then distributed according to type of composite $(\mathrm{C} 1, \mathrm{C} 2, \mathrm{C} 3)$ and photoactivation method (high-intensity $-750 \mathrm{~mW} / \mathrm{cm}^{2}$ for $40 \mathrm{~s}$; low intensity $-150 \mathrm{~mW} / \mathrm{cm}^{2}$ for $200 \mathrm{~s}$; soft-start $-150 \mathrm{~mW} / \mathrm{cm}^{2}$ for $10 \mathrm{~s}+750 \mathrm{~mW} / \mathrm{cm}^{2}$ for $38 \mathrm{~s}$; pulse-delay $-150 \mathrm{~mW} / \mathrm{cm}^{2}$ for $10 \mathrm{~s}+3 \mathrm{~min}$ dark $+750 \mathrm{~mW} / \mathrm{cm}^{2}$ for $38 \mathrm{~s}$ ). Superficial and internal margins were analyzed by scanning electron microscopy, using the epoxy replica technique. The length of gaps was expressed as a percentage of the total length of the margins. Data were submitted to two-way analysis of variance and Tukey's test $(\alpha=0.05)$. Results: Modulated curing methods did not influence gap formation regarding both superficial and internal adaptation. The composite with the lower initiator concentration $(\mathrm{C} 1)$ presented higher gap formation when compared with those with higher concentrations ( $\mathrm{C} 2$ and $\mathrm{C} 3$ ). Conclusion: Modulated photoactivation methods did not reduce gap formation for the experimental composite restorations evaluated. However, higher photoinitiator concentrations promote better marginal seal.

Key words: Camphorquinone, gap formation, modulated photoactivation methods, pulse-delay, resin composites, soft-start

\section{INTRODUCTION}

Resin composites have been widely used in direct esthetic restorative procedures. Despite the development of the resin composites, polymerization shrinkage still harms the interfacial quality. When the shrinkage takes place under confinement, due to bonding to cavity walls, stresses on the bonding interface will develop, ${ }^{[1]}$ potentially leading to gap formation. The presence of gaps on the tooth/resin

\footnotetext{
How to cite this article: Alonso RB, de Souza EJ, Dressano D, de Araújo GS, Rodriguez JC, Hipólito VD, et al, Puppin-Rontani RM, Sinhoreti MC. Effect of photoinitiator concentration on marginal and internal adaptation of experimental composite blends photocured by modulated methods. Eur $\mathrm{J}$ Dent 2013;7:1-8

Copyright (C) 2013 Dental Investigations Society. DOI: $10.4103 / 1305-7456.119056$
} 
interface is considered as the first sign of restoration failure. ${ }^{[2,3]}$

Although polymerization shrinkage is considered the main cause of the adaptation problems of composite restorations, it is an inherent characteristic of the composite and directly related to its composition. ${ }^{[4-6]}$ Moreover, the photoinitiator concentration can influence the shrinkage stress ${ }^{[6]}$ and consequently, the gap formation. However, the effect of photoinitiator concentration in gap formation of composite restorations has not been evaluated.

The most frequently employed photoinitiator on dental composites is camphorquinone (CQ), which is a Type II photosensitizer (it needs a reducing agent to produce free radicals) with a light absorption peak near $468 \mathrm{~nm}$. When CQ is photoactivated, in the excited form, a pair of free radicals is produced by proton abstraction. Such a process can be made highly efficient by the formation of a complex between the photoexcited sensitizer and a reducing agent, such as a tertiary amine. ${ }^{[7]}$

A higher concentration of CQ can induce a quick and high generation of free radicals, yielding the production of a faster polymerization kinetics reaction and higher degree of conversion. ${ }^{[8]}$ As a result, mechanical properties of the material may also be enhanced..$^{[9,10]}$ However, studies have shown that there is an ideal level for the increase of CQ concentration and above this level, the increase in photoinitiator concentration does not benefit the final degree of conversion. ${ }^{[11]}$

Conversely, if the concentration of photoinitiators were kept too low, resin composite could not be satisfactorily cured, ${ }^{[10]}$ which has been associated with poor biocompatibility, ${ }^{[12]}$ color stability, ${ }^{[13]}$ physical and mechanical properties, ${ }^{[14]}$ wear resistance ${ }^{[15]}$ and potentially early failure of the restoration.

In addition, a substantial problem is that CQ is inherently yellow and has poor photobleaching, which means the yellow color remains after light irradiation. It may cause problems in color matching to natural dental substrate ${ }^{[16]}$ and limits the quantity of CQ that can be incorporated in dental composites.

The curing method also manages shrinkage stress and gap formation. ${ }^{[17-19]}$ Modulated photoactivation methods have shown some beneficial effects. ${ }^{[20-22]}$ A slow polymerization reaction allows a slow development of the composite stiffness and leads to better flow that can reduce the shrinkage stress. ${ }^{[18,19,23]}$ Studies have $\mathrm{d}$ emonstrated that the marginal adaptation of resin composites can be improved by light curing with low power density. ${ }^{[17,20,24,25]}$ Conversely, the application of an adequate energy dose for composite curing is necessary to achieve deep and complete polymerization of the material. ${ }^{[26]}$ Thus, modulated curing methods, such as soft-start (SS) and pulse-delay (PD) have been proposed. ${ }^{[17,19,21,24,25,27,28]}$

The SS curing method enhances marginal sealing of cavo-surface margins of composite restoratives, ${ }^{[28]}$ especially due to initial lower viscosity of the composite, allowing a better material flow during the earlier stages of curing. SS also leads to shrinkage, surface hardness and residual monomer concentration similar to conventional photoactivation, in situations with similar radiant exposure. ${ }^{[21]}$ Moreover, the PD photocuring method, which is a variation of the SS method, can also decrease the intensity of polymerization stress. ${ }^{[18,19]}$ This curing method consists of an initial low irradiance exposure followed by a lag period in the absence of the curing light from $10 \mathrm{~s}$ to $5 \mathrm{~min}$ before a final high irradiance exposure. ${ }^{[27,29]}$ The initial low energy density is enough to allow the start of the polymerization reaction of the composite. The lag period increases composite viscous flow. The higher irradiance performed on the last stage of the curing method is responsible for ensuring similar physical and mechanical properties to the composite polymerized using the continuous light method. ${ }^{[19]}$ Some studies have associated this method with reduced gap formation, caused by the reduction of shrinkage stress. ${ }^{[17,27]}$ However, it was also showed that PD method yields the formation of polymers with increased susceptibility to softening in ethanol, even though with similar monomer conversion in comparison with that produced using the continuous light curing technique. ${ }^{[21,30]}$

The effects of modulated photoactivation method have been related to the composition of the resin material. ${ }^{[1,31]}$ However, it is important to consider that most studies evaluating modulated photoactivation methods were conducted using commercial composites where fillers, resin matrix and photo initiation system differ considerably. Therefore, it seems to be more appropriate to use a resin composite model in which the variables could be controlled.

Thus, the aim of this study was to determine the influence of photoinitiator concentration on superficial and internal adaptation of experimental composites 
photocured by different methods. The first tested hypothesis was that a higher concentration of photoinitiator can increase gap formation. The second tested hypothesis was that modulated curing methods reduce gap formation.

\section{MATERIALS AND METHODS}

\section{Formulation of experimental composites}

Monomer mixtures consisting of $65 \mathrm{wt} \%$ of BisGMA (bisphenol-a-glycidyl methacrylate) and $35 \mathrm{wt} \%$ of triethylene glycol dimethacrylate (TEGDMA) were prepared. The light-curing initiator system selected was CQ as photoinitiator and dimethylaminoethyl methacrylate (DMAEMA) as the co-initiator (proportion 1:1 by weight). The light-curing initiator system (CQ/DMAEMA) was thoroughly dissolved in the monomer matrix in the following concentrations: $0.5 \mathrm{wt} \%$ (C1-0.25\% CQ/0.25\% DMAEMA), $1.0 \mathrm{wt} \%$ (C2-0.5\% CQ/0.5\% DMAEMA) and $1.5 \mathrm{wt} \%$ (C3-0.75\% CQ/0.75\% DMAEMA). Furthermore, the inhibitor butylated hydroxytoluene was added to the organic matrix in a concentration of $0.1 \mathrm{wt} \%$ to avoid spontaneous polymerization of the monomers. The organic matrix was reinforced with silanized barium aluminum silicate glass fillers (BaAlSi - average size: $0.5 \mu \mathrm{m}$ ) and silica $\left(\mathrm{SiO}_{2}\right.$ - average size: $\left.0.04 \mu \mathrm{m}\right)$. The fillers were gradually added in the resin matrix and mixed homogeneously to a $65 \mathrm{wt} \%$ loading. Considering this filler content, $80 \mathrm{wt} \%$ were BaAlSi and $20 \mathrm{wt} \%$ were $\mathrm{SiO}_{2}$. The manipulation of the experimental composites was carried out under filtered orange light. The formulation of the experimental composites used in this study was selected based on previous studies. ${ }^{[5,32]}$

\section{Specimen preparation}

A total of 120 bovine incisors were selected, cleaned and stored in a $0.5 \%$ chloramine $\mathrm{T}$ solution at $4^{\circ} \mathrm{C}$ for no more than a week. Roots were sectioned $1 \mathrm{~mm}$ below the cement-enamel junction using a double-face diamond saw (K. G. Sorensen, Sao Paulo, SP, Brazil). The buccal surface was ground on a water-cooled mechanical polisher (Metaserv 2000, Buehler, UK Ltd, Lake Bluff, IL, USA) using 80, 180, 320 and 600 grit silicon carbide $(\mathrm{SiC})$ abrasive paper (Carbimet Disc Set, \#305178180, Buehler, UK Ltd, Lake Bluff, IL, USA) in order to expose a flat enamel area of at least $36 \mathrm{~mm}^{2}$. These teeth were then observed on a stereomicroscope (Zeiss, Manaus, AM, Brazil) at $\times 25$ magnification, to investigate whether the enamel was completely removed.
A cavity with $3 \mathrm{~mm}$ width, $3 \mathrm{~mm}$ length and $2 \mathrm{~mm}$ deep was prepared on the flattened surface using cylindrical diamond tips (\#56, KG. Sorensen, São Paulo, SP, Brazil) mounted in a standard preparation device. In this condition, cavity volume and C-factor were respectively $18 \mathrm{~mm}^{3}$ and 3,6. Diamond tips were replaced after every fifth preparation. At the superficial margin, the cavity walls had a $90^{\circ}$ angle with the dentin surface plane, while the internal cavity angles were rounded due to the design of the diamond tip used. If any sign of pulp exposure was noticed during the cavity preparation, the specimen was discarded.

After cavity preparation, each specimen was restored using an etch-and-rinse adhesive system (Adper Single Bond 2, batch \#3HR, 3M/ESPE, St. Paul, MN, USA), applied in accordance with manufacturer's instructions: Cavity was etched with $35 \%$ phosphoric acid gel (Scotchbond Etchant, 3M/ESPE, St. Paul, MN, USA) for $15 \mathrm{~s}$, rinsed for $10 \mathrm{~s}$ and blot-dried. The adhesive system was applied twice with a $5 \mathrm{~s}$ interval in between, dried carefully with air for $15 \mathrm{~s}$ in order to remove residual solvent (observing a glossy surface) and light cured for $20 \mathrm{~s}$ using a quartz tungsten halogen (QTH) light (XL 2500, 3M/ESPE, St. Paul, MN, USA) with an irradiance of $700 \mathrm{~mW} / \mathrm{cm}^{2}$. Afterward, the teeth were randomly assigned into six groups $(n=10)$, according to the type of composite (C1, C2 and C3) and curing method (high-intensity; low-intensity; SS; PD). Cavities were bulk filled with one of the tested experimental composites. Curing methods are described in Table1. The sameQTH curing unit (XL 2500,3M/ESPE, St. Paul, MN, USA) was used for all curing methods using radiant exposure around $28 \mathrm{~J} / \mathrm{cm}^{2}$. The irradiance was frequently checked by a radiometer (Demetron Research Corp., Danbury, USA).

After the light curing procedures, the specimens were stored in distilled water at $37^{\circ} \mathrm{C}$ for $24 \mathrm{~h}$. After that, the specimens were finished under running water using 600- and 1200- grit SiC abrasive paper (Carbimet Disc Set, \#305178180, Buehler, Lake Bluff, IL, USA) to

\section{Table 1: Curing methods}

\begin{tabular}{ll}
\hline Curing methods & Power density and time exposure \\
\hline High intensity $^{\prime}$ & $700 \mathrm{~mW} / \mathrm{cm}^{2}$ during $40 \mathrm{~s}$ \\
Low intensity $^{\dagger}$ & $150 \mathrm{~mW} / \mathrm{cm}^{2}$ during $187 \mathrm{~s}$ \\
Soft-start $^{\dagger}$ & $150 \mathrm{~mW} / \mathrm{cm}^{2}$ during \\
& $10 \mathrm{~s}+700 \mathrm{~mW} / \mathrm{cm}^{2}$ during $38 \mathrm{~s}$ \\
Pulse delay $^{\dagger}$ & $150 \mathrm{~mW} / \mathrm{cm}^{2}$ during $10 \mathrm{~s}+3 \mathrm{~min}$ light \\
& off $+700 \mathrm{~mW} / \mathrm{cm}^{2}$ during $38 \mathrm{~s}$ \\
\hline The reduction of irradiance was obtained using a standard separator
\end{tabular}

tThe reduction of irradiance was obtained using a standard separator 
expose and polished with $1 \mu \mathrm{m}$ and $0.5 \mu \mathrm{m}$ diamond pastes in a polish cloth under water. Specimens were ultrasonically cleaned for 5 min between finishing and polishing steps.

\section{Evaluation of marginal and internal adaptation by scanning} electron microscopy

In order to evaluate the marginal adaptation of the restorations, impressions were taken with a low viscosity polyvinyl siloxane material (Aquasil, Dentsply DeTrey, Konstanz, Germany) and poured using an epoxy resin (Buehler, Lake Buff, IL, EUA) to obtain replicas. Afterward, the replicas were gold-sputter coated (Balzers-SCD 050 Sputter Coater, Liechtenstein) and observed by SEM (JEOL, JSM-5600 LV, SEM, Japan) for evaluation, measurement and classification of the cavity margins. Replicas were visualized at $\times 25$ and $\times 200$ magnifications. The classification of the margins was made at $\times 200$ magnification directly on the microscope monitor and the measurements were made by using a multi-point measuring device that allowed the observation of the entire perimeter of the restoration at $\times 25$. The perimeter of the restorations was measured and margins were recorded and classified according to the morphologically defined parameters previously described by Kemp-Scholte and Davidson. ${ }^{[33]}$ (1) Perfect margin: Defined as a continuous, gap-free transition between filling and tooth substrate and (2) marginal gap: Observed as gap formation with the loss of interfacial adhesion. Marginal gap formation was calculated and expressed as a percentage of the cavity perimeter of each specimen. The length of the gap formed was calculated as a percentage of the entire margin length.

After the evaluation of superficial adaptation, the restorations were cut in slices ( $1 \mathrm{~mm}$ thick) in the buccal-lingual direction, using a cutting machine (ISOMET 1000, Buehler, Lake Bluff, IL, USA) to obtain three slices of each restoration for internal adaptation measurements. Thus, the sectioned slices were replicated and the internal margins of the restorations evaluated according to the procedures described for the superficial adaptation protocol.

\section{Statistical analysis}

Original gap formation data didn't show normal distribution. For this reason, data were transformed $(x=\operatorname{arcsen} \sqrt{x / 100})$. Aftertransformation, datashowed normal distribution according to Kolmogorov-Smirnov test. Transformed data (gap \%) were subjected to two-way analysis of variance (ANOVA), considering the factors "composite" and "photoactivation method" and Tukey's test at a significance level of $5 \%$. All statistical analysis was executed in Assistat Beta 7.5 software (ASSISTAT - Statistic Assistance by Prof. Dr. Francisco de Assis Santos e Silva, DEAG - CTRN - University of Campina Grande - PB - Brazil).

\section{RESULTS}

Superficial gap formation (\%) means and standard deviations for all photoactivation methods are listed in Table 2. According to two-way ANOVA, for superficial marginal adaptation, only the factor "composite" had statistical differences. The factor "photoactivation method" as well as the interaction between the two factors was not statistically significant. There was no difference between the curing methods, regarding the composite used. In addition, the composite $\mathrm{C} 1$ presented higher gap formation when compared to $\mathrm{C} 2$ or $\mathrm{C} 3$.

Internal gap formation (\%) means and standard deviations for all photoactivation methods are listed in Table 3. As observed for superficial marginal adaptation, only the factor composite showed a significant difference, regardless of the photoactivation method. In the accompanying results of marginal gap formation, there was no difference between the curing methods, regarding the composite used. In addition, the composite $\mathrm{C} 1$ presented higher gap formation when compared to $\mathrm{C} 2$ or $\mathrm{C} 3$.

\begin{tabular}{|c|c|c|c|}
\hline $\begin{array}{l}\text { Photoactivation } \\
\text { methods }\end{array}$ & C1 (0.5\%) & C2 (1\%) & C3 (1.5\%) \\
\hline High intensity & $45.99(21.94)^{\mathrm{aA}}$ & $37.89(23.83)^{\mathrm{aB}}$ & $35.16(17.76)^{\mathrm{aB}}$ \\
\hline Low intensity & $41.64(16.44)^{\mathrm{aA}}$ & $32.20(19.61)^{\mathrm{aB}}$ & $31.55(21.54)^{\mathrm{aB}}$ \\
\hline Soft start & $48.14(16.71)^{\mathrm{aA}}$ & $22.80(20.18)^{\mathrm{aB}}$ & $31.73(21.50)^{\mathrm{aB}}$ \\
\hline Pulse delay & $38.75(17.64)^{\mathrm{aA}}$ & $30.35(22.04)^{\mathrm{aB}}$ & $29.29(17.25)^{\mathrm{aB}}$ \\
\hline
\end{tabular}

Table 3: Internal gap formation (\%) means and standard deviations for all photoactivation methods

\begin{tabular}{llll}
$\begin{array}{l}\text { Photoactivation } \\
\text { methods }\end{array}$ & C1 (0.5\%) & C2 (1\%) & C3 (1.5\%) \\
\hline High intensity & $22.6(12.54)^{\mathrm{aA}}$ & $1.5(2.46)^{\mathrm{aB}}$ & $0.0(0.00)^{\mathrm{aB}}$ \\
Low intensity & $04.0(05.87)^{\mathrm{aA}}$ & $0.0(0.00)^{\mathrm{aB}}$ & $0.0(0.00)^{\mathrm{aB}}$ \\
Soft start & $16.7(10.12)^{\mathrm{aA}}$ & $0.0(0.00)^{\mathrm{aB}}$ & $0.0(0.00)^{\mathrm{aB}}$ \\
Pulse delay & $10.2(07.45)^{\mathrm{aA}}$ & $0.0(0.00)^{\mathrm{aB}}$ & $0.0(0.00)^{\mathrm{aB}}$ \\
\hline
\end{tabular}

aA, aBMean values followed by different small letters in the column and capital letters in the row differ statistically among themselves for the Tukey test at the level of $5 \%$ 


\section{DISCUSSION}

Photoinitiatorconcentrationis a fundamental parameter that determines the polymerization characteristics of a resin composite. ${ }^{[32]}$ This concentration varies among the commercial composites ${ }^{[34,35]}$ and its effects on marginal and internal adaptation are not still completely elucidated. Taira et al. ${ }^{[34]}$ found CQ concentrations that range from 0.17 to $1.03 \mathrm{wt} \%$ of the resin and Shintani et al. ${ }^{[35]}$ reported a range of 0.03-0.09 $w t \%$ of the dental composite.

In this study, the concentration of CQ ranged from 0.25 to $0.75 \mathrm{wt} \%$ of the resin matrix (which corresponds to $0.087-0.26 \mathrm{wt} \%$ of the composite) and it has affected superficial and internal gap formation. However, this effect was opposite that expected: The composite with lower concentration of initiators (C1) presented a higher gap percentage then composites with a higher concentration (C2 and C3), rejecting the first hypothesis. Alonso et al. ${ }^{[9]}$ using the same composite formulation as the present work, found a significant reduction of monomer conversion when $\mathrm{C} 1(0.5 \%$ of CQ) was compared to C3 (1.5\% of initiator), showing that the higher the initiator concentration, the higher the conversion degree. In this sense, it was expected that $\mathrm{C} 3$ would present higher gap formation, since a higher degree of conversion means higher shrinkage, higher elastic modulus and higher stress at the bonding interface. ${ }^{[1,36]}$ However as stated, C1 restorations showed the highest incidence of gaps. This condition was attributed to the formation of a deficient polymer network. The poorly polymerized composite would not adequately bond to the adhesive resin, allowing gap formation, as observed in Figure 1.

Photoinitiator concentration of a resin composite must be sufficient to allow an adequate polymerization. An insufficient polymerization would affect biocompatibility of the composite, due to residual monomer release. Geurtsen et al. ${ }^{[37]}$ showed that CQ and TEGDMA are released to the aqueous substrate by unsatisfactory polymerized resin materials and can damage oral tissue when presented in high concentration. In addition, bonding problems, like the ones demonstrated in the present study [Figure 1], can also occur in composite restorations with inadequate polymerization. However, it is important to consider that CQ/amine concentration should be as low as possible due to its yellowing effect, which can cause difficulty in matching dental color and also the tendency to internal discoloration yielded by amine. ${ }^{[32,38]}$ So, considering the composites evaluated in this study, $1 \%$ of CQ/amine (C2) could be

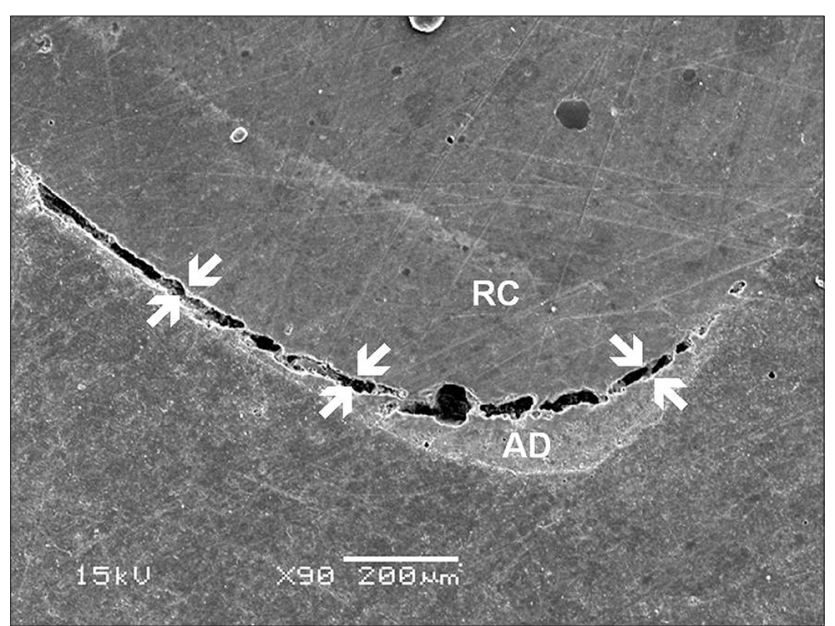

Figure 1: Gap formation in restoration filled with the experimental composite $\mathrm{C} 1$ (between arrows). The failure occurs between the restorative composite and the adhesive layer, what could be related to the poor polymerization of the composite. RC: Restorative composite, AD: Adhesive layer

considered to be adequate since it is sufficient to guarantee a satisfactory polymerization and marginal seal, since C2 and C3 present similar gap formation [Tables 2 and 3] and a similar degree of conversion, according to Alonso et al. ${ }^{[9]}$

A satisfactory marginal seal of composite restorations is important for its clinical success. Esthetics and bond durability of these restorations are directly influenced by the marginal seal. ${ }^{[39]}$ In general, the origin of gaps has been related to three main factors: Contraction stress of composite restoratives, ${ }^{[40]}$ bonding failures, ${ }^{[41,42]}$ and external mechanical or thermal stress. ${ }^{[43,44]}$ In the present study, specimens were not submitted to any mechanical or thermal stress and bonding procedures were standardized for all groups. This condition enabled the evaluation of gap formation as a result of contraction stress of the experimental composites with different photoinitiator concentrations and different curing methods. Therefore, it is important to state that besides the care taken during specimen preparation, gap formation studies usually show high variability of the data, as inside each group some specimens present a perfect seal while others present a high percentage of gaps. Data variability in gap formation studies can be attributed to the great variability of the dental substrate, especially considering bonding to dentin. ${ }^{[41]}$ For this reason, it is important to use a minimum of 10 specimens per group.

The majority of the specimens showed a perfect seal of the superficial enamel margins in the present study, as observed in Figure 2. Enamel presents high mineral content, allowing good and stable bond strength when 
the etch-and-rinse technique is used. These results are in accordance with the studies of Correr et al. ${ }^{[45]}$ and Alonso et al. ${ }^{[2]}$ Regarding internal adaptation, gap formation was more frequently observed at the axiopulpal angle and pulpal wall. Misfit at the angle may be attributed to the more complex accommodation of the composite in this region, as observed in Figure 3. In addition, stress concentration on the cavity angle and on defects at the adhesive layer contribute to misfit. ${ }^{[4]}$ On the pulpal wall, gaps can be attributed to the greater complexity of adhesion due to the higher density and diameter of dentin tubules, decreasing the intertubular area that is essential for bonding. ${ }^{[41]}$

Another studied factor was the curing protocol. It was hypothesized that modulated photoactivation methods could reduce gap formation (second hypothesis). However, this hypothesis was not confirmed in this study. Modulated curing methods did not improve marginal or internal adaptation of composite restorations, corroborating Lopes et al. ${ }^{[46]}$ and Amaral et al. ${ }^{[47]}$

Irradiance can directly influence the polymerization rate, which is related to shrinkage stress development. ${ }^{[48]}$ The higher polymerization rate decreases composite flow, leading to more frequent gap formation on the tooth/restoration interface due to the fast development of rigidity, reducing the viscoelastic period. ${ }^{[48]}$ Thus, the increase of elastic modulus added to polymerization shrinkage yields stress development at the bonding interface, which has been related to marginal adaptation failure of composite restorations. ${ }^{[49]}$ In this sense, the low irradiance method or the modulated ones can be

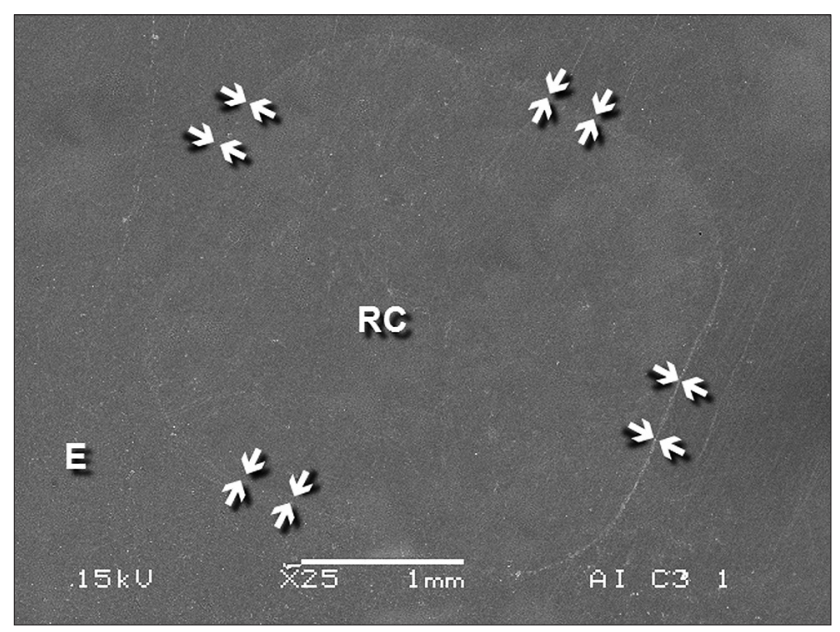

Figure 2: Photomicrography of restoration with perfect marginal seal. Between the white arrows, it can be observed the sealed enamel margins. Most of specimens showed perfect marginal seal. E: Enamel, RC: Restorative composite convenient by reducing the polymerization rate, which favors a slower contraction stress development. ${ }^{[18]}$ On the other hand, this effect was not able to reduce gap formation in the present study. This suggests that the effects of reduced curing rates on contraction stress are limited and significant reductions in stress can be verified only after the curing rate drops below a certain threshold, as stated by Braga et al. ${ }^{[50]}$ In this sense, it could be speculated that the determinant factor for gap formation would be the energy dose applied, so that composites photocured with similar energy density presents similar gap formation. This speculation is supported by others studies ${ }^{[1,50,51]}$ considering that the total volumetric contraction of a composite and maximum stress of this system depend on monomer conversion, which is energy-dose-dependent. ${ }^{[51]}$ Alonso et al..$^{[9]}$ showed that the degree of conversion of the composites tested here was similar for all photoactivation methods as the same energy dose was applied.

Some studies have shown that the efficacy of modulated methods vary according to composite formulation. ${ }^{[5]}$ In this way, modulated methods would show beneficial effects only for specific formulations. Another disadvantage of these methods is the decrease of cross-link density on polymer network, caused by the lower irradiance application, ${ }^{[21,30]}$ yielding the composite matrix to be more susceptible to degradation.

In accordance with the results of the present study, resin composites with different photoinitiator concentration show different marginal and internal adaptation features, perhaps due to the polymerization behavior. However, it is not affected by modulation of light intensity; composite restoration photocured by modulated methods presents similar marginal quality as the energy dose was kept constant. Thus, only the understanding of the problem statement, allied to the development of techniques to reduce their consequences, would help clinicians to obtain

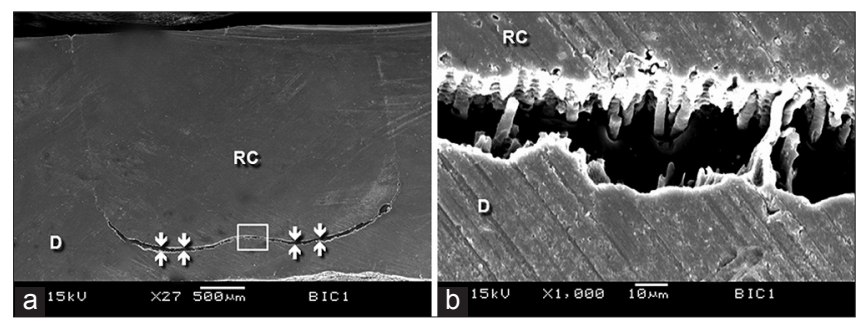

Figure 3: Photomicrography of internal gap formation. (a) Presence of gap at the axiopulpal angle and pulpal wall. The loss of interfacial adhesion can be observed. (b) Gap between dentin and restorative composite. D: Dentin, RC: Restorative composite 
the maximum benefits of resin composite restorations in clinical practice.

\section{CONCLUSION}

Modulated photoactivation methods did not reduce gap formation of composite restorations. Therefore, higher photoinitiator concentrations in composite allow better marginal seal for the tested conditions. The composite with $0.5 \%$ of photoinitiators yielded increased superficial and internal gap formation.

\section{ACKNOWLEDGMENT}

This investigation was supported by FAPESP (Process \# 2008/56194-0).

\section{REFERENCES}

1. Braga RR, Ballester RY, Ferracane JL. Factors involved in the development of polymerization shrinkage stress in resin-composites: A systematic review. Dent Mater 2005;21:962-70.

2. Hilton TJ. Can modern restorative procedures and materials reliably seal cavities? In vitro investigations. Part 2. Am J Dent 2002;15:279-89.

3. Hilton TJ. Can modern restorative procedures and materials reliably seal cavities? In vitro investigations. Part 1. Am J Dent 2002;15:198-210.

4. Amirouche-Korichi A, Mouzali M, Watts DC. Effects of monomer ratios and highly radiopaque fillers on degree of conversion and shrinkage-strain of dental resin composites. Dent Mater 2009;25:1411-8.

5. Atai M, Watts DC, Atai Z. Shrinkage strain-rates of dental resin-monomer and composite systems. Biomaterials 2005;26:5015-20.

6. Schneider LF, Consani S, Sakaguchi RL, Ferracane JL. Alternative photoinitiator system reduces the rate of stress development without compromising the final properties of the dental composite. Dent Mater 2009;25:566-72.

7. Ikemura K, Endo T. A review of the development of radical photopolymerization initiators used for designing light-curing dental adhesives and resin composites. Dent Mater J 2010;29:481-501.

8. Pfeifer CS, Ferracane JL, Sakaguchi RL, Braga RR. Photoinitiator content in restorative composites: Influence on degree of conversion, reaction kinetics, volumetric shrinkage and polymerization stress. Am J Dent 2009;22:206-10.

9. Alonso RC, Correr GM, Cunha LG, Brandt WC, Puppin-Rontani RM, Correr Sobrinho L, et al. Photoinitiator concentration and modulated-photoactivation: Influence on polymerization characteristics of experimental-composites. J Dent Res 2008;87:Abstract 1801.

10. Musanje L, Ferracane JL, Sakaguchi RL. Determination of the optimal photoinitiator concentration in dental composites based on essential material properties. Dent Mater 2009;25:994-1000.

11. Yoshida K, Greener EH. Effect of photoinitiator on degree of conversion of unfilled light-cured resin. J Dent 1994;22:296-9.

12. Nomura Y, Teshima W, Kawahara T, Tanaka N, Ishibashi H, Okazaki $\mathrm{M}$, et al. Genotoxicity of dental resin polymerization initiators in vitro. J Mater Sci Mater Med 2006;17:29-32.

13. Asmussen E. Factors affecting the color stability of restorative resins. Acta Odontol Scand 1983;41:11-8.

14. Ferracane JL, Greener EH. The effect of resin formulation on the degree of conversion and mechanical properties of dental restorative resins. J Biomed Mater Res 1986;20:121-31.

15. Ferracane JL, Mitchem JC, Condon JR, Todd R. Wear and marginal breakdown of composites with various degrees of cure. J Dent Res 1997;76:1508-16.

16. Alvim HH, Alecio AC, Vasconcellos WA, Furlan M, de Oliveira JE, Saad JR. Analysis of camphorquinone in composite resins as a function of shade. Dent Mater 2007;23:1245-9.
17. Alonso RC, Correr GM, Cunha LG, De Moraes Souto Pantoja CA, Puppin-Rontani RM, Sinhoreti MA. Modulated photoactivation methods - Effect on marginal and internal gap formation of restorations using different restorative composites. J Biomed Mater Res B Appl Biomater 2007;82:346-51.

18. Cunha LG, Alonso RC, Pfeifer CS, Correr-Sobrinho L, Ferracane JL, Sinhoreti MA. Modulated photoactivation methods: Influence on contraction stress, degree of conversion and push-out bond strength of composite restoratives. J Dent 2007;35:318-24.

19. Cunha LG, Alonso RC, Pfeifer CS, Correr-Sobrinho L, Ferracane JL, Sinhoreti MA. Contraction stress and physical properties development of a resin-based composite irradiated using modulated curing methods at two C-factor levels. Dent Mater 2008;24:392-8.

20. Alonso RC, Cunha LG, Correr GM, De Goes MF, Correr-Sobrinho L, Puppin-Rontani RM, et al. Association of photoactivation methods and low modulus liners on marginal adaptation of composite restorations. Acta Odontol Scand 2004;62:298-304.

21. Brandt WC, de Moraes RR, Correr-Sobrinho L, Sinhoreti MA, Consani S. Effect of different photo-activation methods on push out force, hardness and cross-link density of resin composite restorations. Dent Mater 2008;24:846-50.

22. Souza-Junior EJ, de Souza-Régis MR, Alonso RC, de Freitas AP, Sinhoreti MA, Cunha LG. Effect of the curing method and composite volume on marginal and internal adaptation of composite restoratives. Oper Dent 2011;36:231-8.

23. Cunha LG, Alonso RC, de Souza-Junior EJ, Neves AC, Correr-Sobrinho L, Sinhoreti MA. Influence of the curing method on the post-polymerization shrinkage stress of a composite resin. J Appl Oral Sci 2008;16:266-70.

24. Alonso RC, Cunha LG, Correr GM, Cunha Brandt W Correr-Sobrinho L, Sinhoreti MA. Relationship between bond strength and marginal and internal adaptation of composite restorations photocured by different methods. Acta Odontol Scand 2006;64:306-13.

25. Alomari QD, Barrieshi-Nusair K, Ali M. Effect of C-factor and LED curing mode on microleakage of class $\mathrm{v}$ resin composite restorations. Eur J Dent 2011;5:400-8.

26. Lindberg A, Peutzfeldt A, van Dijken JW. Effect of power density of curing unit, exposure duration, and light guide distance on composite depth of cure. Clin Oral Investig 2005;9:71-6.

27. Lim BS, Ferracane JL, Sakaguchi RL, Condon JR. Reduction of polymerization contraction stress for dental composites by two-step light-activation. Dent Mater 2002;18:436-44.

28. Yoshikawa T, Burrow MF, Tagami J. A light curing method for improving marginal sealing and cavity wall adaptation of resin composite restorations. Dent Mater 2001;17:359-66.

29. Sahafi A, Peutzfeldt A, Asmussen E. Effect of pulse-delay curing on in vitro wall-to-wall contraction of composite in dentin cavity preparations. Am J Dent 2001;14:295-6.

30. Asmussen E, Peutzfeldt A. Influence of pulse-delay curing on softening of polymer structures. J Dent Res 2001;80:1570-3.

31. Yazici AR, Celik C, Dayangac B, Ozgunaltay G. Effects of different light curing units/modes on the microleakage of flowable composite resins. Eur J Dent 2008;2:240-6.

32. Park YJ, Chae KH, Rawls HR. Development of a new photoinitiation system for dental light-cure composite resins. Dent Mater 1999;15:120-7.

33. Kemp-Scholte CM, Davidson CL. Complete marginal seal of Class V resin composite restorations effected by increased flexibility. J Dent Res 1990;69:1240-3

34. Taira M, Urabe H, Hirose T, Wakasa K, Yamaki M. Analysis of photo-initiators in visible-light-cured dental composite resins. J Dent Res 1988;67:24-8.

35. Shintani H, Inoue T, Yamaki M. Analysis of camphorquinone in visible light-cured composite resins. Dent Mater 1985;1:124-6.

36. Calheiros FC, Daronch M, Rueggeberg FA, Braga RR. Influence of irradiant energy on degree of conversion, polymerization rate and shrinkage stress in an experimental resin composite system. Dent Mater 2008;24:1164-8.

37. Geurtsen W, Spahl W, Leyhausen G. Variability of cytotoxicity and leaching of substances from four light-curing pit and fissure sealants. J Biomed Mater Res 1999;44:73-7.

38. Moin Jan C, Nomura Y, Urabe H, Okazaki M, Shintani H. The relationship between leachability of polymerization initiator and degree of conversion of visible light-cured resin. J Biomed Mater Res 2001;58:42-6. 
39. Larson TD. The clinical significance of marginal fit. Northwest Dent 2012;91:22-9

40. Irie M, Suzuki K, Watts DC. Marginal gap formation of light-activated restorative materials: Effects of immediate setting shrinkage and bond strength. Dent Mater 2002;18:203-10.

41. Marshall GW Jr, Marshall SJ, Kinney JH, Balooch M. The dentin substrate: Structure and properties related to bonding. J Dent 1997;25:441-58.

42. Bechtold J, Dos Santos PJ, Anido-Anido A, Di Hipólito V, Alonso RC, D'Alpino PH. Hardness, polymerization depth, and internal adaptation of Class II silorane composite restorations as a function of polymerization protocol. Eur J Dent 2012;6:133-40.

43. Frankenberger R, Pashley DH, Reich SM, Lohbauer U, Petschelt A, Tay FR. Characterisation of resin-dentine interfaces by compressive cyclic loading. Biomaterials 2005;26:2043-52.

44. Momoi Y, Iwase H, Nakano Y, Kohno A, Asanuma A, Yanagisawa K. Gradual increases in marginal leakage of resin composite restorations with thermal stress. J Dent Res 1990;69:1659-63.

45. Correr GM, Bruschi Alonso RC, Puppin-Rontani RM, Correr-Sobrinho L, Coelho Sinhoreti MA. Marginal and internal adaptation of composite restorations using a resin liner on deproteinized substrate. Acta Odontol Scand 2005;63:227-32.

46. Lopes MB, Costa LA, Consani S, Gonini AJ, Sinhoreti MA. SEM evaluation of marginal sealing on composite restorations using different photoactivation and composite insertion methods. Indian J Dent Res 2009;20:394-9.
47. Amaral CM, Peris AR, Ambrosano GM, Pimenta LA. Microleakage and gap formation of resin composite restorations polymerized with different techniques. Am J Dent 2004;17:156-60.

48. Kinomoto Y, Torii M, Takeshige F, Ebisu S. Comparison of polymerization contraction stresses between self- and light-curing composites. J Dent 1999;27:383-9.

49. Davidson CL, Feilzer AJ. Polymerization shrinkage and polymerization shrinkage stress in polymer-based restoratives. J Dent 1997;25:435-40.

50. Braga RR, Ferracane JL. Contraction stress related to degree of conversion and reaction kinetics. J Dent Res 2002;81:114-8.

51. Calheiros FC, Kawano Y, Stansbury JW, Braga RR. Influence of radiant exposure on contraction stress, degree of conversion and mechanical properties of resin composites. Dent Mater 2006;22:799-803.

\begin{tabular}{|l|l|}
\hline \multicolumn{2}{|c|}{ Access this article online } \\
\hline Quick Response Code: & Website: \\
& www.eurjent.com \\
\cline { 2 - 3 } & $\begin{array}{l}\text { Source of Support: This investigation } \\
\text { was supported by FAPESP (Process \# } \\
\end{array}$ \\
& 2008/56194-0). \\
& Conflict of Interest: None declared \\
\hline
\end{tabular}

\section{“QUICK RESPONSE CODE” LINK FOR FULL TEXT ARTICLES}

The journal issue has a unique new feature for reaching to the journal's website without typing a single letter. Each article on its first page has a "Quick Response Code". Using any mobile or other hand-held device with camera and GPRS/other internet source, one can reach to the full text of that particular article on the journal's website. Start a QR-code reading software (see list of free applications from http://tinyurl.com/yzlh2tc) and point the camera to the QR-code printed in the journal. It will automatically take you to the HTML full text of that article. One can also use a desktop or laptop with web camera for similar functionality. See http://tinyurl.com/2bw7fn3 or http://tinyurl.com/3ysr3me for the free applications. 